\title{
LONG-TERM MECHANICAL BEHAVIOR OF SOME ODS ALLOYS
}

\author{
R. C. Benn and S. K. Kang \\ Inco Alloy Products Company Research Center \\ Inco - Sterling Forest \\ P.O. Box 200 \\ Suffern, NY 10901
}

\begin{abstract}
One of the major attributes of oxide dispersion strengthened (ODS) alloys is that they can retain useful strengths up to a relatively high fraction of their melting points. Moreover, at the higher operating temperatures characteristic of advanced gas turbine engines, these alloys display long-term strengths beyond the capabilities of conventional superalloys. Determination of the long term mechanical properties and related microstructures of ODS alloys such as INCONEL* alloy MA 6000 has identified some unique stress rupture behavior characteristics, particularly the existence of two distinct regions of the rupture stress vs. time curves that predict higher design stresses for long time service than could be predicted from only short term data. This paper describes this behavior and discusses the advantages for industrial applications. These findings will affect both the application of current ODS superalloys and the development of new materials.
\end{abstract}

\section{Introduction and Background}

The problem of determining component performance from laboratory tests is fundamental in materials engineering. Frequently high temperature strength data are needed for conditions where there is no experimental information. This is particularly true for long-time creep and stress rupture data where it is quite possible for the design engineer to require the creep strength to give $1 \%$ deformation in $100,000 \mathrm{~h}$ $(\checkmark 11$ years) when the commercial alloy has only been in existence for about 2 years. The increasing use of ODS alloys, particularly in industrial applications, has created a need to measure the creep rupture performance of these alloys and to predict their behavior in long-term service.

A program has therefore been underway at the IAPC Research Center to characterize the long-term mechanical properties and related microstructures of these alloys. Apart from providing design data, this study is providing insight into the mechanisms that give rise to the outstanding long-term high temperature strengths. The data presented here are primarily from tests on INCONEL* alloy MA 6000, which is a $\gamma^{\prime}$ phase $(\backsim 50$ vol.\%) strengthened ODS superalloy. Information on the mechanical and microstructural behavior of this alloy after long-term, stressed high temperature exposure has been obtained. The implications to the design engineer of these unique stress rupture properties at both intermediate and high operating temperatures will be discussed. Some reference to majority $\gamma$ phase oDs superalloys such as Alloy 51 and non- $\gamma$ phase strengthened ODS superalloys such as INCONEL

* Trademark of the Inco family of companies. 
alloy MA 754 (see Table I) will be made for comparison. Finally the significance of these observations for work in progress on new ODS superalloys will be briefly discussed with particular reference to alloy property requirements for industrial gas turbine engines.

Table I. Alloy Compositions (Wt.96)

\begin{tabular}{|c|c|c|c|c|c|c|c|c|c|c|c|c|c|}
\hline Alloy & $\overline{\mathrm{Cr}}$ & Mo & $\bar{W}$ & $\overline{\mathrm{Al}}$ & $\mathrm{Ti}$ & $\mathrm{Ta}$ & $\mathrm{B}$ & $\mathrm{Zr}$ & C & $\mathrm{Co}$ & Nb & $\mathrm{Y}_{2} \mathrm{O}_{3}$ & $\mathrm{Ni}$ \\
\hline & 15 & 2.0 & 4.0 & 4.5 & 2.5 & 2.0 & .01 & 0.15 & 0.05 & - & - & 1. & Be \\
\hline EL alloy $M$ & 20 & - & - & 0.3 & 0.5 & - & - & - & 0 . & - & - & 0. & \\
\hline All & 9.5 & 3.4 & 6.6 & 8.5 & - & - & 0.01 & 0.15 & 0.05 & - & - & 1.1 & $"$ \\
\hline IN-939 & 22 & - & 2.0 & 1.9 & 3.7 & 1.4 & 0.009 & 0.10 & 0.15 & 19 & 1.0 & $=$ & \\
\hline
\end{tabular}

Experimental Data and Analysis

Creep and stress rupture data for this study were compiled from ongoing tests at the IAPC Research Center and supplemented with other available data (1-4). A conventional Larson-Miller plot of alloy MA 6000 rupture data is given in Figure 1 below.

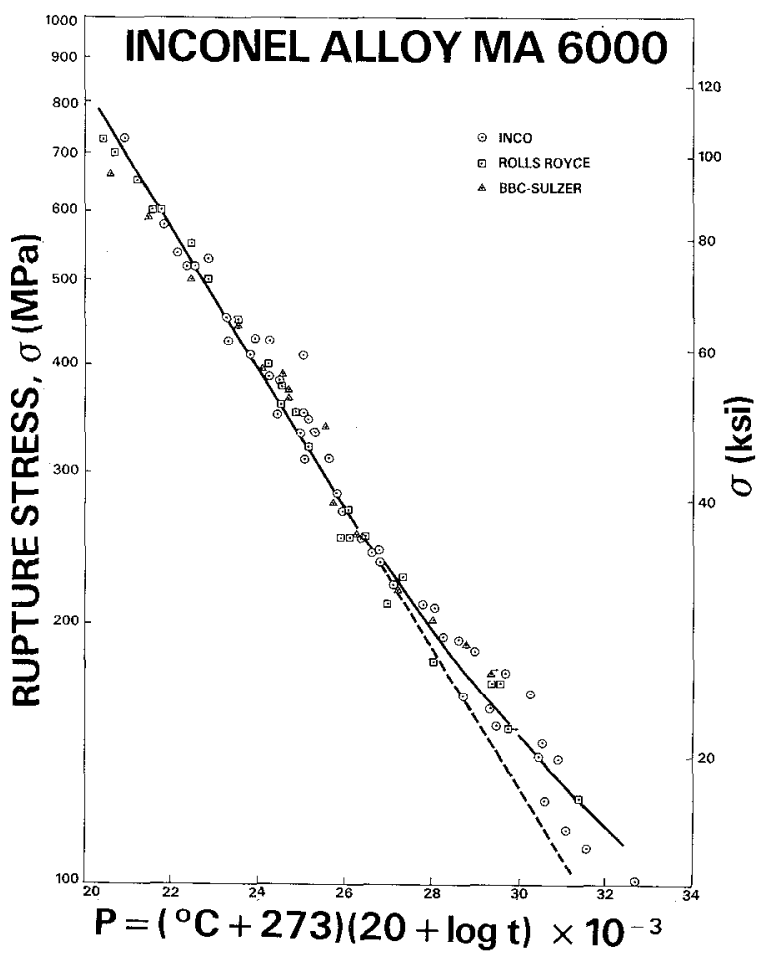

Figure 1 - Larson-Miller curve $(t=$ rupture life, $h)$

Figure 1 indicates the unusual behavior of the alloy in that the rupture strength decreases slowly at high temperatures and results in a leveling off of the curve. The Larson-Miller parameter is not recommended for extrapolated estimates of long-time strengths, which are better determined from long term rupture test data plots of stress vs. time to failure at various temperatures. Figure 2 shows that, when such stress $(\sigma)$ and time $(\mathrm{t})$ data are plotted on log-log scales, there is some evidence of an upward inflection in the curves for a wide range of test temperatures. The locus of the inflection point is given approximately by the dotted curve in Figure 2. When the data are plotted as stress $(\sigma)$ vs. $\log t$ (Figure 3 ), the upward inflection is clearly evident as a very significant characteristic of the rupture behavior of this ODS superalloy. The presence of this inflection portends a higher long-term strength capability in this material than indicated from extrapolation of short-term data (see below). There is insufficient creep data at present to determine whether the minimum creep rate $(\dot{\varepsilon})$ values also level off beyond the inflection points. 


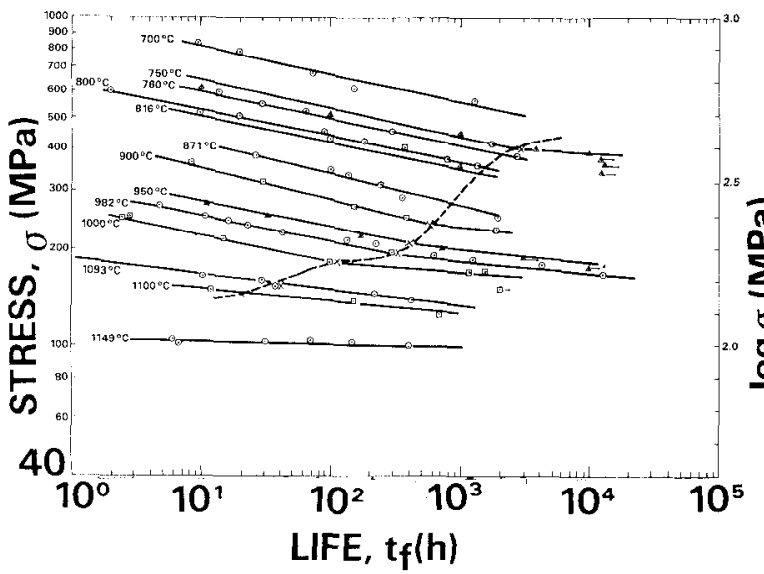

Figure 2 - Stress rupture plot for INCONEL alloy MA $6000(\log \sigma$ vs. $\log \mathrm{t}$ ).

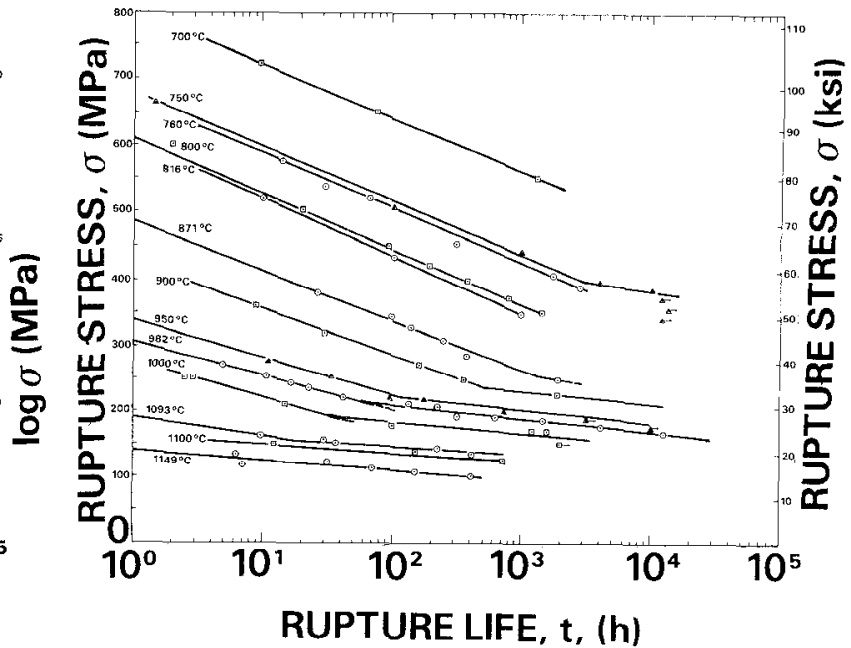

Figure 3 - Stress rupture plot for INCONEL alloy MA 6000 ( $\sigma$ vs. $\log \mathrm{t}$ ).

Apart from the excellent high temperature performance, there is considerable interest in the long term behavior of INCONEL alloy MA 6000 and related ODS alloys at intermediate temperatures, e.g., $750-950^{\circ} \mathrm{C}$, for industrial and some aerospace applications. In these regions of the stress rupture plot where some long-term data is not presently available, estimates of rupture strength may be obtained as follows. Generally, $\dot{\varepsilon}$ and rupture life $(t)$ are related by the equation

$$
\dot{\varepsilon} \mathrm{t}^{\alpha}=\mathrm{A}_{1}
$$

where $A_{1}$ is a constant and $\alpha \approx 1$, indicating the mechanisms involved are the same. At low applied stresses ( $\sigma<2 \times 10^{-4} \mathrm{E}$ where $\mathrm{E}$ is Young's Modulus) the creep rate is frequently correlated as

$$
\dot{\varepsilon}=A_{2}\left(\frac{\sigma}{E}\right)^{n} \exp \left(\frac{-Q}{R T}\right)
$$

where $\mathrm{A}_{2}$ is a structure dependent parameter while $\mathrm{n}$ and $\mathrm{Q}$ are the apparent stress exponent and activation energy, respectively. Equation [2] yields anomalously high values of $n$ and $Q$ when applied to ODS alloys and has been rationalized by describing creep rate in terms of an effective stress which is the applied stress minus a threshold stress $\left(\sigma_{\text {th }}\right)$ resisting creep. This modification is reviewed elsewhere (cf. Ref. 5). For the purposes of the present study, equations [1] and [2] may be combined to yield an equation which for a given rupture life reduces to the form:

$$
\log \left[\frac{\sigma}{\mathrm{E}}\right]_{\mathrm{T}}=\left(\frac{\mathrm{Q}}{2.303 \mathrm{nR}}\right) \frac{1}{\mathrm{~T}}+\mathrm{A}_{3}
$$

Hence known INCONEL alloy MA 6000 rupture life data - and some linear extrapolations of alloy MA 6000 data that were justified by actual performance of similar ODS alloys such as alloy MA 753 (3) -- were used to derive Figure 4. This plot permits estimation of long term rupture lives as shown in Figure 5, and thus guides the choice of stress levels in creep rupture tests.

The above analysis indicates the existence of two distinct areas in Figure 5, identified as Regions I and II, with an interface defined by the estimated locus of the inflection points. This unique behavior has important material design implications because the long-term stress capability of INCONEL alloy MA 6000 in the temperature range of, say, $750-1000^{\circ} \mathrm{C}$ is superior to initial estimates derived by extrapolation of relatively short-term data. Estimates of the long term rupture stress capability in the $10^{4}-10^{5} \mathrm{~h}$ life range at a given temperature should be made strictly by using data beyond the inflection point of the stress rupture curve. 


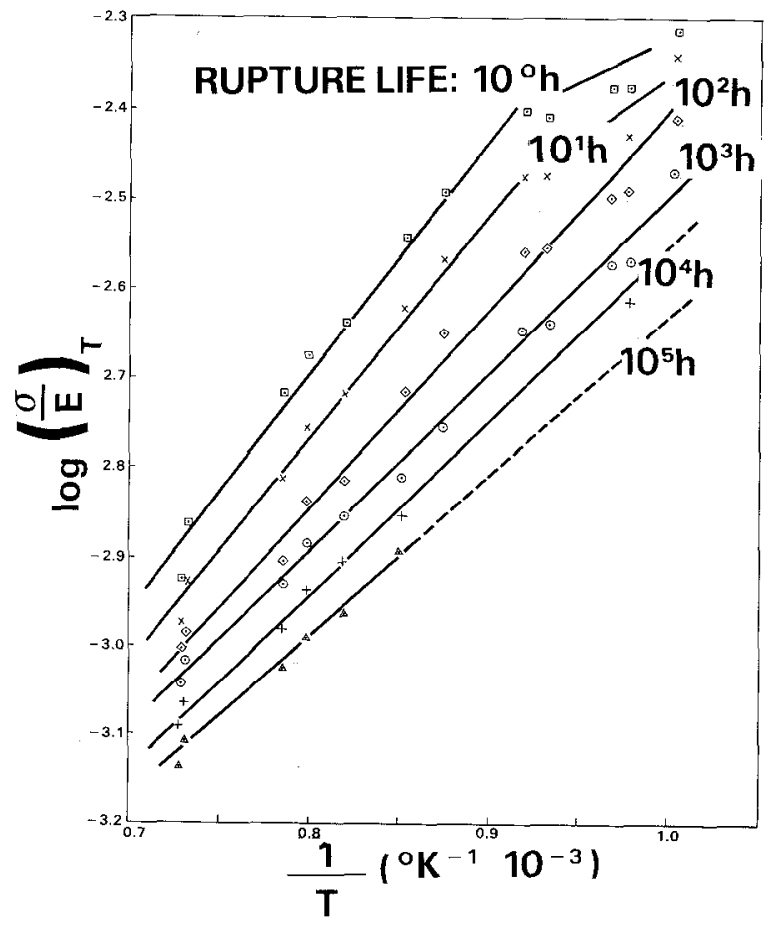

Figure 4 - Variation of modulus compensated stress with reciprocal temperature for INCONEL alloy MA 6000.

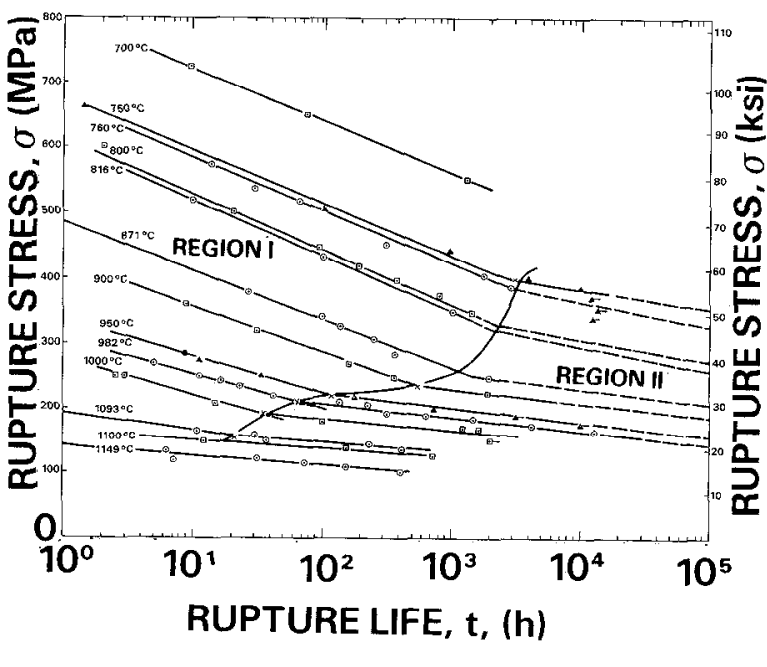

Figure 5 - Stress rupture plot identifying Region I and II behavior of INCONEL alloy MA 6000.

\section{Discussion}

The locus of the inflection points in Figure 5 is a complex function defined by the intersection of two property surfaces that characterize the behavior of the alloy in Regions I and II respectively. Each surface is a function, inter alia, of T, $\sigma, \gamma^{*}$ phase volume fraction and dispersoid parameters. It appears likely that $\gamma$ phase and dispersoid parameters predominantly influence the behavior in Regions I and II, respectively. Specifically, it must be assumed that the $\gamma^{\circ}$ contributes strongly to $\sigma_{\text {th }}$ at intermediate temperatures, e.g., $760^{\circ} \mathrm{C}$, but not at $950-1150^{\circ} \mathrm{C}$ because of the temperature dependence of the $\gamma$ phase volume fraction. The effect of the dispersoids is largest at the highest temperatures and longest lives because $\gamma$ phase becomes the least effective under these conditions and because the threshold is approached.

Figures 6 and 7 show the morphological changes in the $\gamma^{*}$ phase during creep. Evidence of $\gamma^{\prime}$ phase coarsening and rafting is observed at the higher test temperatures. Alignment of the $\gamma$ phase was observed both perpendicular and at acute angles to the applied stress. Consequently, the direction of rafting scems more directly related to the direction of the slip (system) orientation than to the direction of the applied stress. If the direction of rafting is perpendicular to the stress axis, a strengthening effect can be obtained as in certain single crystal alloys with [100 ] textures (6). Rafting in INCONEL alloy MA 6000, which nominally has a [110] texture, was generally observed in material tested in Region II only and may contribute to the observed strength. 


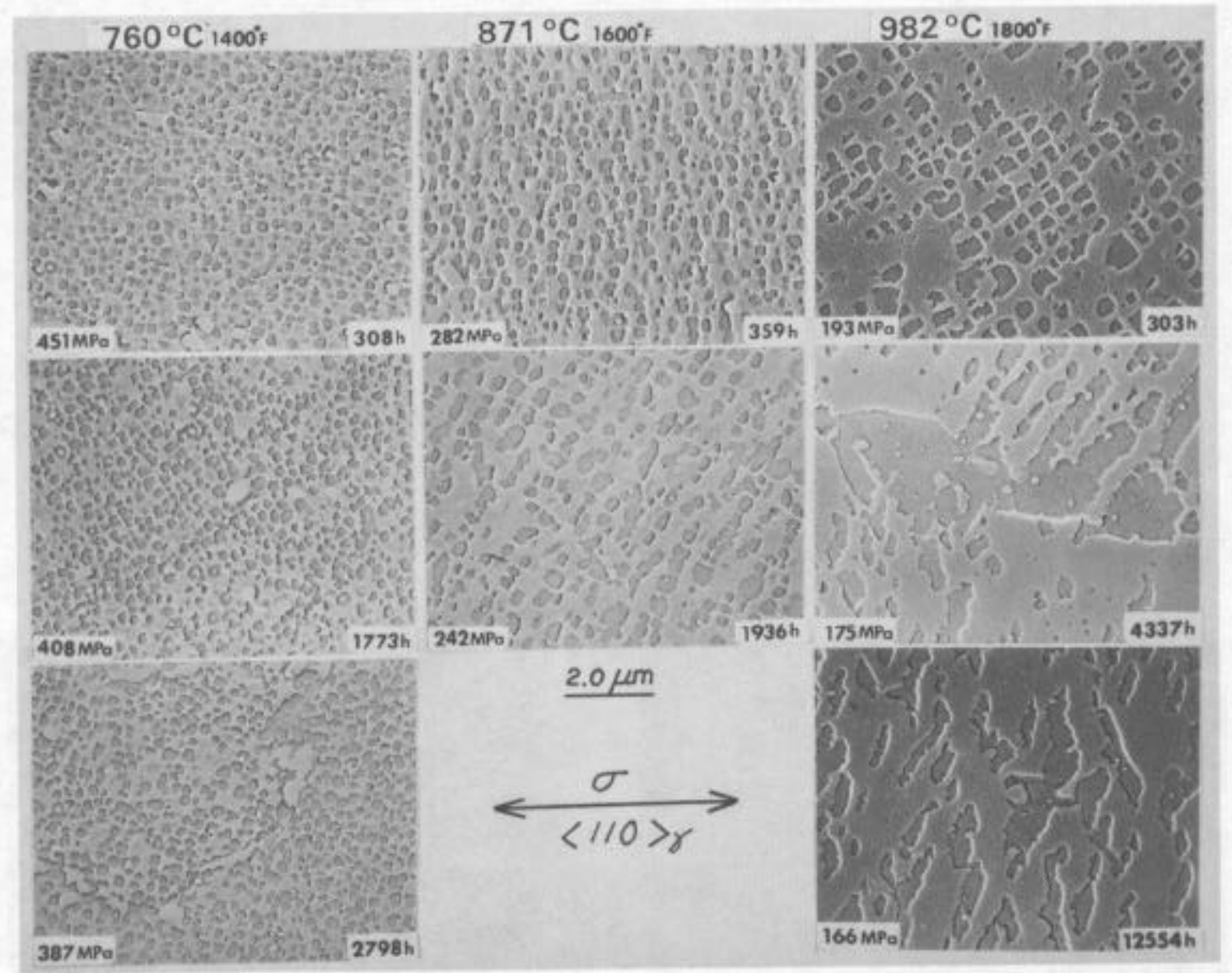

Figure 6 - Replica electron micrographs of INCONEL alloy MA 6000 illustrating variation in $\gamma$ morphology with stress rupture conditions.

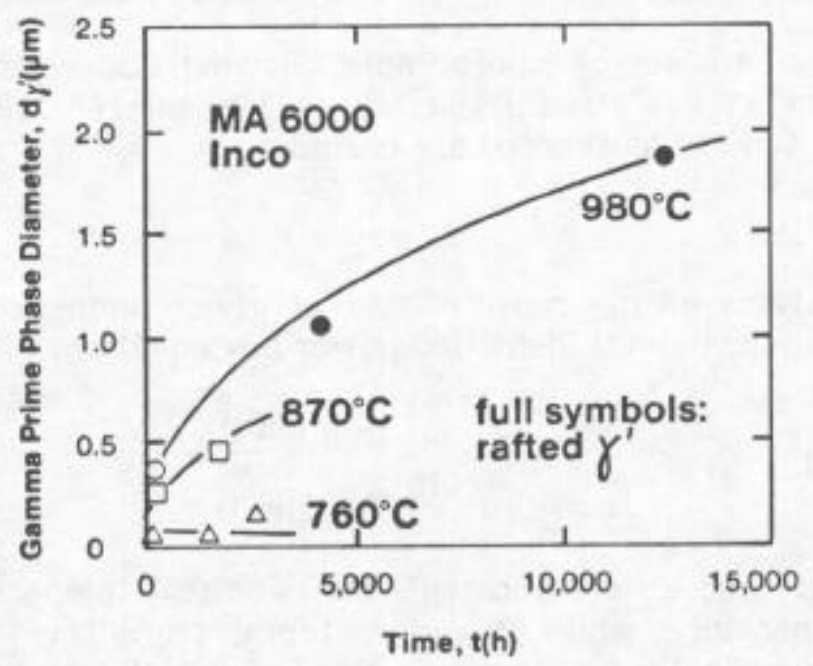

Figure 7 - Variation of $\gamma$ phase size (weighted average diameter) with rupture life.

Figure 8 indicates that after stress rupture exposures at $750-760^{\circ} \mathrm{C}$, there is negligible dispersoid coarsening. At higher temperatures around $950-980^{\circ} \mathrm{C}$, there
appears to be some increase in dispersoid size at rupture lives beyond $10^{4} \mathrm{~h}$ (Figure 9). However, Figure 5 shows that these changes cause no serious loss in the load-bearing capability of the alloy for practical applications. 


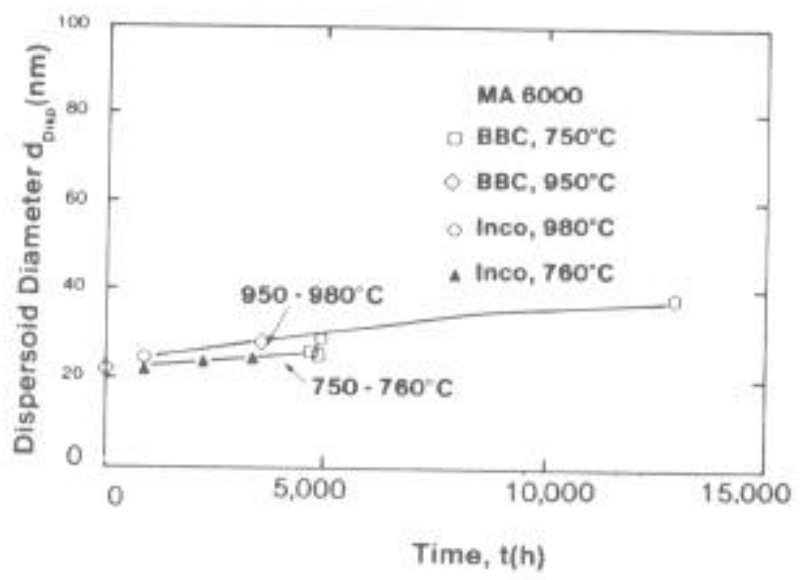

Figure 8 - Variation of dispersoid size (weighted average diameter) with rupture life.
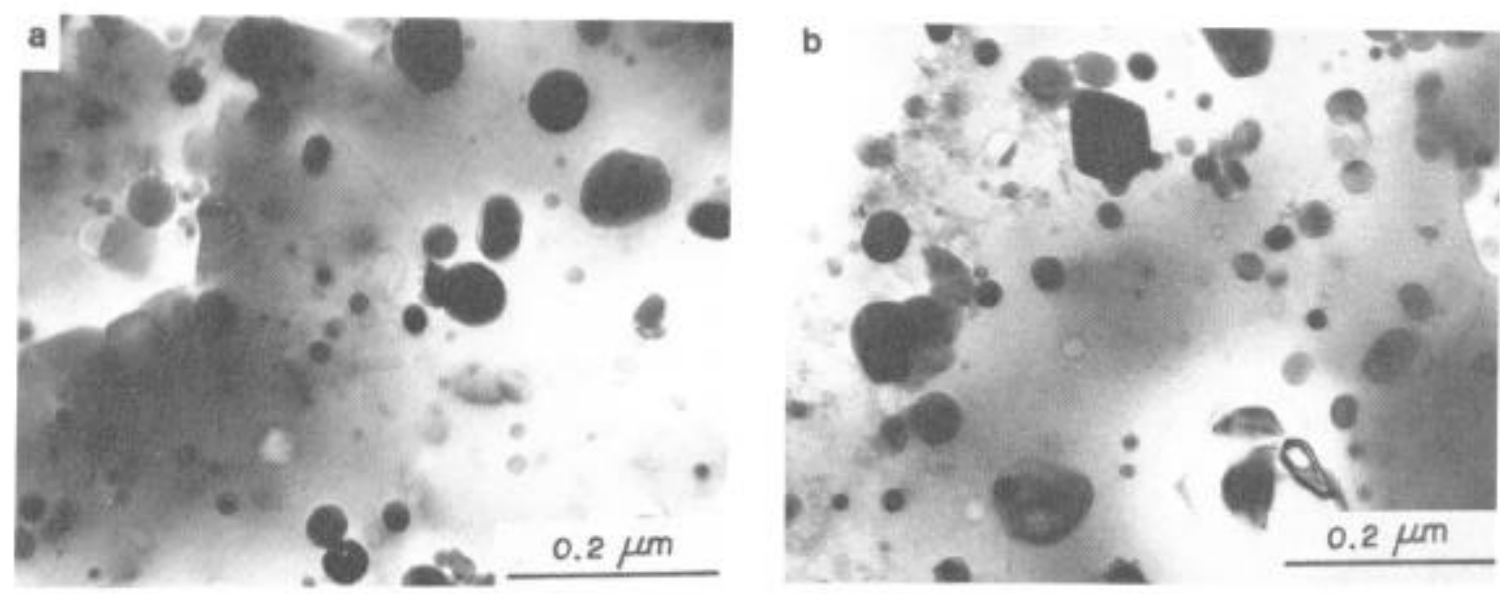

Figure 9 - Transmission electron micrographs showing dispersoid morphology after stress rupture testing at $982^{\circ} \mathrm{C}$ : (a) $193 \mathrm{MPa} / 303 \mathrm{~h}$, (b) $166 \mathrm{MPa} / 12,554 \mathrm{~h}$. Note: larger particles that tend to be faceted are carbides.

\section{Alloy Design Implications}

Numerical analyses of the rupture data at given temperatures for INCONEL alloy MA 6000 in Regions I and II identified power law equations of the form:

and

$$
\sigma=\mathrm{K}_{1} \mathrm{t}^{-\mathrm{m}^{1}} \text { (Region } \mathrm{I} \text { ) }
$$

$$
\sigma=\mathrm{K}_{2} \mathrm{t}^{-\mathrm{m}_{2}} \text { (Region II) }
$$

to be the best fit. $\mathrm{K}_{1}$ and $\mathrm{K}_{2}$ are constants for each test temperature that decrease with increasing temperature, while at a given temperature $\left|\mathrm{m}_{1}\right|$ was approximately 2-4 times $\left|\mathrm{m}_{2}\right|$. Specifically for Region $\mathrm{I},\left|\mathrm{m}_{1}\right| \leq 0.05-0.1$ and for Region $\left.\Pi \mid \mathrm{m}_{2}\right\}$ $\simeq$ 0.025-0.05. Combining equations [1] and [2] to solve for $\sigma$ at constant $T$ produces:

$$
\sigma=\mathrm{K} \mathrm{t}^{-\alpha / \mathrm{n}}
$$

This equation is identical to the power law form of equations [4 ] and [5 ] derived numerically and indicates that $|\mathrm{m}|=|\alpha / \mathrm{n}|$. Assuming $\alpha \approx 1$, values of the stress exponent, $\mathrm{n}$, are thus calculated to be in the range 10-20 (Region I) and 20-40 (Region II), which is in good agreement with values obtained from $\varepsilon$ measurements (3). This 
correlation confirms the validity of using stress rupture data, in the absence of creep data, to predict long-term performance of ODS alloys.

A similar power law equation relating stress and time provided the best fit to the available data for the boundary curve between Regions I and II. While the above equations are empirical representations of very complex phenomena, they serve as guides to ODS superalloy development applications such as industrial gas turbines.

Figure 10 illustrates the effects of alloy design on stress rupture characteristics. Alloy 51 has a much higher $\gamma$ phase volume fraction $(\varsigma 70 \%)$, which improves Region I performance compared to INCONEL alloys MA 6000 ( $\left.\backsim 50 \% \gamma^{\circ}\right)$, MA $754(0 \%)$ and cast IN-939 ( $\backsim 27 \%)$. These trends have also been quantified using equations [4] and [5]. All three ODS alloys show unique long term strength capability typical of Region II that greatly surpasses IN -939 at temperatures around $982^{\circ} \mathrm{C}$ (INCONEL alloy MA 754 essentially shows only Region II characteristics). High $\mathrm{Cr}$ alloys such as IN-939, however, display better hot corrosion resistance than these ODS alloys in industrial gas turbine environments. While INCONEL alloy MA 6000 has excellent corrosion resistance in applications for which it was designed, such as advanced aerospace gas turbines, new ODS superalloys are being developed (7) for industrial applications that require extremely high corrosion resistance typical of IN-939. The $10^{4}-10^{5} \mathrm{~h}$ rupture strength requirements of these new alloys will particularly benefit from Region II characteristics.

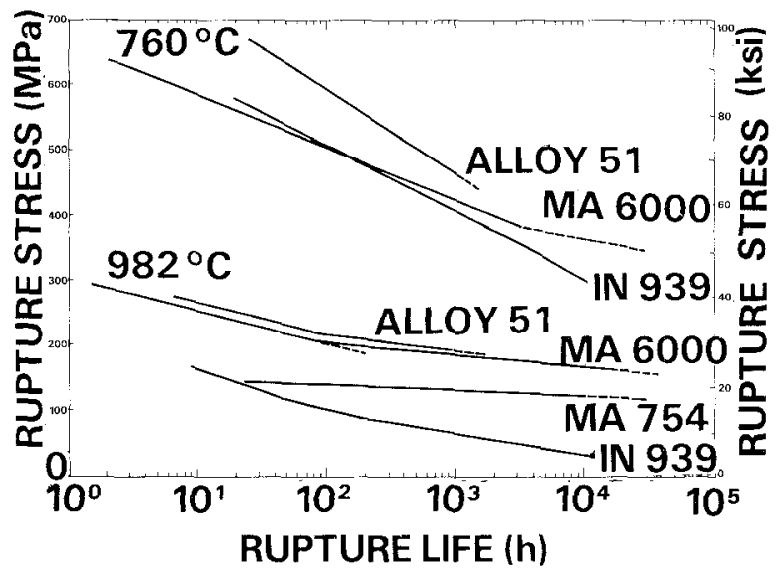

Figure 10 - Effect of alloy design on stress rupture characteristics.

\section{Conclusion}

Studies of the long-term stress and creep rupture characteristics of ODS alloys have identified unique stress-rupture behavior that implies significant advantages over conventional alloys for acrospace and industrial applications. Region I and II behavior is observed in $\gamma^{\prime}$ phase-containing ODS alloys such as INCONEL alloy MA 6000 and Alloy 5l, while INCONEL alloy MA 754, with no $\gamma$ phase, shows only Region II behavior. Regions I and II appear to be $\gamma^{*}$ phase and dispersoid dependent, respectively.

\section{References}

1. IncoMAP Engineering Data Sheets on INCONEL alloys MA 6000 and MA 754, Inco Ltd. 1981.

2. R. G. Wing, "The Development of an ODS Turbine Blade Alloy (INCONEL alloy MA 6000) for Use in Small Gas Turbine Engines" in "Frontiers of High Temperature Materials II", Conf. Proc., London, May 1983, to be published through IncoMAP. 
3. R. F. Singer, R. C. Benn and S. K. Kang, "Creep Rupture Properties of INCONEL alloy MA 6000", ibid. Ref. 2 .

4. R. C. Benn, "Oxide Dispersion Strengthened High Volume Fraction $\gamma$ Nickel Base Superalloy Characterization", Report No. NADC-79106-60, Naval Air Systems Command, May 1981.

5. C. M. Sellars and R. A. Petkovic-Luton, "Creep of Dispersion-Strengthened Alloys", Mats. Sei. and Eng'g., 46, pp. 75-87 (1980).

6. D. D. Pearson, F. D. Lemkey and B. H. Kear, "Stress Coarsening of $\gamma^{*}$ and Its Influence on Creep Properties of a Single Crystal", in "Superalloys 1980", J. K. Tien et al. (Eds.), ASM, 513, 1980.

7. R. C. Benn, IAPC Research Center, unpublished research. 